\title{
A MULTI STAGED METHOD FOR SELECTION OF BPM SOFTWARE
}

\author{
*Batuhan KOCAOGLU (Orcid ID: 0000-0002-6876-1362) \\ *Asena Hacere TUNCER (Orcid ID: 0000-0001-9085-228X) \\ *Cemre AYDIN (Orcid ID: 0000-0001-6356-8953) \\ *Ece BARUTÇU (Orcid ID: 0000-0002-0497-3956) \\ *Efekan METİOĞLU (Orcid ID: 0000-0001-9575-6713) \\ *Piri Reis University, Turkey
}

\begin{abstract}
Purpose - Interest in business process management among users is growing every day. Business process management (BPM) is one of the drivers of digital transformation. There are several different tools that focus on various aspects of BPM. Thus, it is difficult to choose the most suitable solution among them. The purpose of this article is to select the BPM software that best fits the criteria, after determining the criteria to be considered.

Design/methodology/approach - This article provides a multi staged method for determining the criteria that can be used when selecting BPM software that is planned to be purchased in a particular company. Additionally, this study concluded with the selection of the most appropriate BPM solution. The multi staged method is based on NGT, Delphi and AHP.

Findings: A comprehensive list of BPM system selection factors are created after an in-depth study of the literature. Proposed approach is applied to a problem of decision-making process in a company. An initial investment into the right BPM software could save companies more in the long term than they would expect.

Originality: Even though there are many studies related to enterprise software selection such as ERP and $C R M$, there are few studies about BPM software selection. With its multi staged structure focus on BPM software, it differs from the software selection literature.
\end{abstract}

Keywords: business process management; business process management software; selection criteria; NGT; Delphi; MCDM; AHP

\section{INTRODUCTION}

In the last decade, Business Process Management has gained an important role in business communities. In the ideal case of BPM, companies can provide better service to their customers and improve their performance in general. Recent experimental research on the links between Business Process Management and customer satisfaction has confirmed that process management is a critical part of technical service quality (Štemberger \& Vuksic, 2009). There are several BPM principles and methods that are being used in different management applications.

A number of software tools used in business process management is called BPM Software. There are several different tools which are focused on different sections of BPM. For instance, organization modelling, enterprise modelling, process modelling, simulation and optimization business rule management, managing relationships between process participants, monitoring process performance, process automation, workflow management and also, software modelling and development.

The structure of this article is as follows; the first section includes the definitions of BPM, BPMS, NGT Method, Delphi Method and MCDM (AHP). The second section encompasses the case application of determining BPM selection criteria and the overall conclusion is in the final section.

\section{BUSINESS PROCESS MANAGEMENT (BPM)}

Business Process Management is an organizational discipline in which a company looks at all of its processes in total and one-on-one. BPM provides an analysis of the current state and identifies areas which can be improved to make a more efficient and more effective organization (Kissflow, 2020). 
Today's business environment is evolving at a quick speed, and businesses must adapt to these changes at the same rate. When we review the researches, we notice that complicated business models are one of the most significant barriers to firms achieving long-term efficiency and profitability. Conveniences are offered in business processes while producing products and delivering services when the right steps applied.

Since the Industrial Revolution, business process management (BPM) has been a broad framework for managing and changing the processes that impact corporate performance. BPM is a system that integrates information from management sciences with current technology and adapts it to business activities. The level of interest is growing by the day as a result of the visible rise in production and cost reductions (Sebetci, Günay, \& Sebetci, 2018).

When the business processes are unorganized, it can lead to chaos. At the individual level, workers only see one side of a process, and very few can realize and see the full picture as to, how a process begins and ends, and where potential bottlenecks and inefficiencies may hamper the workflow. If there is no BPM in the company:

- Time will be wasted

- There will be more errors

- There will be more blame

- There will be lack of data

- There will be demoralized employees (Kissflow, 2020).

\section{Types of BPM platforms}

BPM platforms can divide into four categories:

- Basic BPM Platform: Basic BPM platform has a graphical business process modelling, and it can also make rule modelling. Basic BPM platform has DW (Data Warehouse) for modelling metadata. The execution of basic BPM platform is engine and state management engine.

- BPMS (Business Process Management Suite): Modelling of the BPMS is a model driven composition environment. BPMS uses registry storage for process components. The process execution of BPMS is state management engine. BPMS makes rule management via business rules management. In BPMS, users and groups collaborate with each other. On the content repository side, it has document and content interaction. BPMS has basic connectivity and can connect with other devices easily. Business event support and BAM (Business Activity Monitoring) are used for monitoring. BPMS uses simulation and optimization in order to improve itself. BPMS controls via management and administration.

- IBPMS (Intelligent Business Process Management): The models of the IBPMS are model driven composition environment and prototyping. IBPMS uses registry storage for process components. IBPMS executes via process orchestration engine, ACM (Adaptive Case Management) and, unstructured process support. IBPMS makes rule management with business rules management and scenario policy management. IBPMS provides collaboration with human interaction management, social media integration and mobility. On the content repository side, it has content interaction management and big data. IBPMS enables integration via connectivity \& integration, mobility, social media integration, big data and, IoT. Active analytics, process mining, BAM (Business Activity Monitoring) and CEP (Complex Event Processing) are used for monitoring. IBPMS uses on-demand analytics in order to improve itself. IBPMS controls via management and administration (Robledo, 2018).

- BPMN (Business Process Model and Notation): BPMN allows to clearly and consistently handle and report an organization's business processes, and includes process owners and stakeholders in to the process. The team can respond more effectively and quickly to all issues described in the processes with BPMN. BPMN can be understood by technical and non-technical stakeholders, because of the notations the software had. (Seysane, 2018)

\section{Steps of a BPM Lifecycle}

The BPM life cycle requires phases for managing business processes. It outlines activities that are part of BPM initiatives. The phases of BPM life cycle vary in terms of number and nomenclature (Zuhaira \& Ahmad, 2020). In this study it is summarized the generic steps as follows:

- Designing: These processes include a form to collect the data and to process a workflow. Creating a process form and identifying who will be responsible for each job in the workflow.

- Modelling: Modelling, represents the process in a visual layout. It includes fixing details such as deadlines and conditions. 
- Execution: Execution phase includes deploying and going live with the designed model. Also, the company must make sure to restrict access to secret information.

- Monitoring: Observe the process as it runs through the workflow. Using the proper metrics is important in identifying progress, measuring efficiency, and locating bottlenecks.

- Optimization: When analyzing the executed process, an employee in charge must notice any changes that need to be done to the form or workflow to make them more efficient according to business process improvement steps (Kissflow, 2020).

\section{Business Process Management Software (BPMs)}

BPM software (BPMs) is a process automation tool. BPMs is used for identifying and eliminating bottlenecks, controlling company costs, making processes run as efficient as possible to ensure the effectiveness of the persons involved and helps with planning the daily processes.

"Business process management software frequently focuses on allowing non-IT specialists to build business workflows, with an emphasis on connecting disparate systems. BPM tools usually make their capabilities accessible through a visual process modelling and design tool that allows relatively non-technical users to design and test processes and workflows. BPM tools include a range of capabilities to serve this core workflow function" (TrustRadius, 2020):

Workflow management: Users can design, test, and execute complex workflows to manage the interactions between employees, systems, and data. Many of these workflows are automated by the BPM platform.

Business rules engine: Users can create complex sets of business rules and conditions as part of process design and execution.

Form generator: Users can build web-forms without programming or coding skills.

Collaboration: The software often supports things like discussion threads, decision management, and idea management.

Analytics: Users can define metrics and KPIs, and run standard and custom reports.

Integrations: Key integrations enable businesses to use data across systems and interfaces, such as MS SharePoint and Salesforce.

Today, many organizations are turning to business process management software to gain a competitive advantage in order to thrive in the business world. The BPM focuses on driving industrial value by optimizing business processes through its various features. It could be useful to your organization in many ways regardless of how you implement the software. Some of the benefits of business process management software are:

- Improved Productivity: By automating unnecessary items in a workflow, BPM software can maximize productivity within a business area and allow employees to concentrate their time and resources on more productive areas.

- Increasing Efficiency and Reducing risks: By using BPMs, better created, planned, implemented and monitored business processes can be built. These provide an increase in efficiency.

- Satisfaction of Employee: BPM automation largely eliminates repetitive tasks, allowing employees to perform their daily tasks with relative ease.

- Integration of Technology: Business process management software allows the mobile support feature to bridge the gap between businesses and information technology.

- Cost Efficiency: By streamlining business processes, automating routine activities, tracking key metrics, and simulating workflows, integrated BPM solutions allows you to optimize profits and minimize expenses.

- Better Customer Relations: It provides a forum which allows better and easier engagement with your customers.

- Ease of Use: The business process management software's versatile and user-friendly interface enables you to transform complex process types to visuals that are easier to understand (PAT Research, 2018). 


\section{ORIGINALITY OF THE STUDY}

BPM software is an important issue for many companies. Even though there are many studies related to software selection, there are few studies like (Brkić, Tomičić Pupek, \& Bosilj Vukšić, 2020) (Zuhaira \& Ahmad, 2020) about BPM software selection. It also is a difficult task to select the most compatible software for the company. Various methods can be used to ease the companies' selection process. This study aims to use some methods simultaneously and getting suitable selection criteria and software. There are many articles written on how to improve the existing BPM software, but the aim of this study is to make a whole new BPM selection criterion for a glass factory. Selecting a suitable BPM will be a good beginning for the companies which are in digital transformation process.

\section{PROBLEM DEFINITION}

Today, many companies have started to prefer BPM software to digitize and optimize their business processes. Although BPM software will benefit the company with proper use, it contains high costs during its procurement. In order to ensure that the investments are not wasted, the software to be purchased must be determined according to certain criteria. The criteria and the software chosen must be consistent within themselves in mathematically, as well as expressing the firm's expectations from the software.

\section{SOLUTION APPROACH}

To select the most suitable solution for a company, a hybrid methodology is proposed. Flowchart of the steps of the solution is described in Figure 1.

Figure 1: Flowchart of the Solution Approach

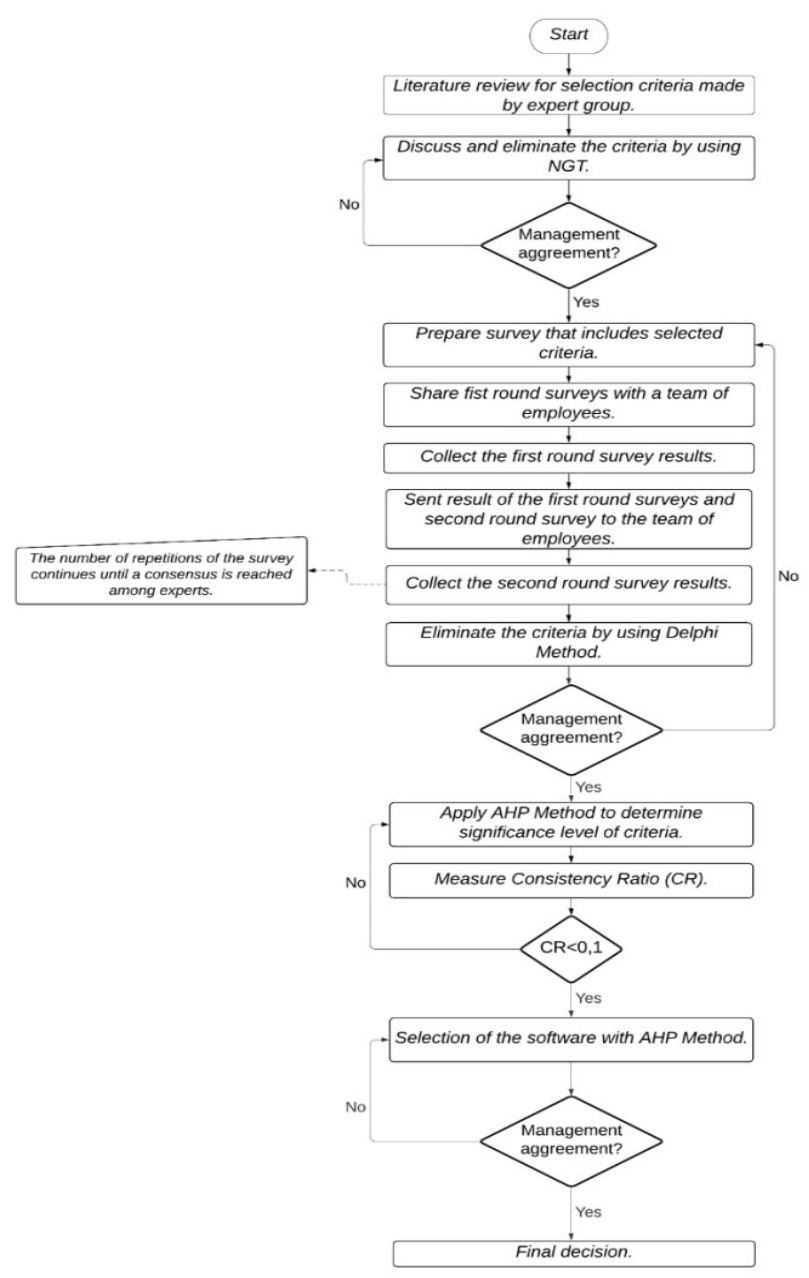


The details will be described in the following sections.

The criteria that would be taken into account in the selection of BPM Software with literature review were determined by the expert group. Some of these criteria were eliminated by using the NGT conducted among the expert group. Surveys were prepared to implement the Delphi method. Prepared surveys were then sent to the team of employees and asked to be answered. The answered surveys were collected and the results were shared with the team of employees. Surveys were sent back for a second round to the employees who reviewed their answers along with the results of the first round surveys. After the surveys in the second round were collected, some criteria were eliminated based on the obtained results. The significance level of the remaining criteria was determined by the AHP method. Consistency analysis of the results was performed. A comparison was made between BPM software alternatives according to the significance level of the criteria selected using the AHP method.

The methods will be described in the following sections.

\section{Nominal Group Technique (NGT)}

Nominal group technique (NGT) is a decision-making method in which all group members participate and provide a rapid consensus regarding the decision-making process. NGT is a technique developed as an alternative to the brainstorming technique. The advantages of this technique include that participants have equal voice, scoring anonymously, and creating a suitable environment for the entire decision-making process (Macphail, Nominal group technique: a useful method for working with young people, 2001).

In the 1960s, NGT was developed as a strategy to aid in effective group decision-making in social psychology research (Harvey \& Holmes, 2012). The usage of NGT reported for the first time in 1975. Since then, NGT has been used as an evaluation technique in medical, health care, nursing, engineering, information and systems, management, and behavioral research to prioritize things and highlight areas that require attention or improvement. NGT aims to provide the appropriate procedure in order to obtain reliable and qualitative information in the studies in which is used.

The steps of the NGT are briefly as follows:

1. Idea generation: A group is formed, and group members express their opinions in writing. A quiet environment is provided for participants to focus and generate ideas. They usually are given a span of 5-10 minutes to generate ideas. This period can be increased depending on the situation. This step is completed when all ideas are shared with the group.

2. Interpretation and explanation: The generated ideas are presented for discussion to be interpreted and explained. Similar and complementary ideas can be combined and grouped by the participants. As a result of this, clustered ideas are listed.

3. Voting: This is the step where the ideas are voted on. In the voting process, the participants are asked to score the ideas in the list individually. In this step, the ideas with letters are scored in order of importance. Points opposite the letter corresponding to the ideas are then added up. The ideas that get the highest score as a result of this step are the ideas chosen by the team.

4. Final discussion: The ideas selected according to the scoring made in the previous step are told to all the participants and presented for their comments. At the end of this process, a consensus is reached, and a group report is created (Şen \& Cenkçi, 2009).

\section{Delphi Method}

The Delphi technique was named after a series of studies (interviews, surveys) done by Rand Corporation Company in the 1950s to estimate the quantity of bombs in the US target system from the perspective of Soviet Strategic Planner specialists (Dalkey \& Helmer, 1963). The Delphi method or approach is defined as the process through which a group of specialists uses a shared judgement to establish consensus about an event or phenomena. This method is a means of organizing communication among a group of people who can give effective support in addressing a complicated problem (Landeta, Barrutia, \& Lertxundi, 2011). When the literature on the Delphi methodology is reviewed, it is seen that it is utilized alone or in conjunction with other methodologies in many business domains or scenarios. The Delphi approach has been developed as a versatile and adaptable method for collecting and analyzing necessary data for those involved or interested in research, evaluation, fact finding, problem research, or determining what is truly known about a particular topic (Hsu \& Sandford, 2007). 
Delphi Method is based on the assumption that data from a group is more accurate than data from individuals. The aim is to identify, examine and reconcile the perspectives of experts or representatives of the target audience against the problem in the focused field. Because the Delphi Method aims to highlight ideas rather than individuals, it is based on the principle of confidentiality in participation.

The Delphi Method is an effective method of gathering the opinions of experts who are in different places and difficult to come together for various reasons. Participants, who do not come face to face while using the Delphi Method, will be able to freely come up with their own ideas without being subjected to pressure from others. They will also have the opportunity to reconsider their own ideas through the results of the survey (ŞAHIN, 2001).

The steps of the Delphi Method are briefly as follows:

1. A panel of experts is formed.

2. Surveys prepared on the subject are sent to the experts and they are asked to complete these surveys.

3. Analysis results obtained from collected surveys are sent to the experts.

4. According to the results of the survey in the first round, another survey is sent to the experts who review their own answers. Experts fill out this questionnaire again, taking into account the results they have seen.

5. After the surveys collected in the second round are analyzed, the results are sent to the experts once again.

6. The number of repetitions of the survey continues until a consensus is reached among experts (Bruin \& Rosemann, 2007).

\section{MCDM (Multi-Criteria Decision Making)}

Sometimes, it can be difficult for companies to make a decision. For instance, when the case has a huge count of possibilities to compare or when there is a significant number of decision-makers, or when the results of actions are not reliable. Therefore, some companies are using Multiple Criteria Decision-Making (MCDM) in order to consider various criteria. Multi-criteria decision-making is generally the last threshold of the decision-making in the business process. (Ghlala, Kodia, \& Said, 2017)

\section{Methods of MCDM}

There are so many different types of multi-criteria decision-making methods. Some methods of MCDM are Analytic Hierarchy Process (AHP), Elimination and Choice Translating Reality (ELECTRE), Technique for Order Preference by Similarity to Ideal Solution (TOPSIS), etc.

MCDM has two subheadings as Multi-Objective Decision Making (MODM) and Multi-Attribute Decision Making (MADM). The main difference between these two subheadings is the determination of the alternatives. The alternatives of MODM are not predetermined, but a collection of functions are optimized subject to a collection of constraints. The alternatives of MADM are predetermined, a small number of alternatives are evaluated against a number of attributes. The best alternative is chosen based on the comparison of the attribute of the alternatives. (Ghlala, Kodia, \& Said, 2017)

MCDM evaluates various criteria and sorts these criteria according to the opinions of various industry experts. The MCDM methods can decrease the time and cost of the decisions while increasing their accuracy. It also creates an appropriate framework for solving problems. Through this feature of the MCDM, decision-makers of the companies can analyze and sort the requirements of the problem easily. This method presumes that each alternative is evaluated according to each criterion therefore; the compromised ranking evaluates the measure of proximity to the ideal alternative. In order to calculate the compromise ranking, the LP-metric is used as an aggregating function.

Here is an example of MCDM steps in a production factory:

1. Calculation of quantities of critical indicators for production lines.

2. Determination of weights between indicators.

3. Sorting production lines with MCDM methods.

4. Sorting production lines with the aggregate method.

5. Discussion and Interpretation of answers.

The results of the methods can be different due to the use of various methods. If the results of all the methods are similar, it means that all the used methods are correct and they can be used for ranking and comparison. 
But if the results of the methods are not similar, it is hard to make a comparison. In this situation, it is better to use the exploiting aggregate methods to the indication of the best solution. At this point, the results of these methods are compared with the aggregate methods, the optimal method is any of the MCDM methods that have a comparable result with aggregate (Pourjavad \& Shirouyehzad, 2011).

\section{AHP Technique}

The Analytic Hierarchy Process (AHP) is one of the most used techniques of the Multi Criteria Decision Making Method. The AHP utilizes probabilistic measurement with dominance matrices. In the process of making and evaluating a collection of simple reciprocal pair wise comparison matrices, a tradeoff arises. It is possible to create a pair wise comparison of the various elements where the values in each cell indicate the dominance of each element over another with respect to some given criterion. The largest eigenvalue may arise from this scaling formulation for each hierarchy.

The following steps are followed when using AHP:

1. The pair wise comparison of evaluation criteria according to current factors.

2. Finding the supporting intensity of each criterion according to each alternative.

3. Synthesis of the results obtained from previous steps to find the final priorities.

4. Consistency analysis to check the sustainability of final results under various conditions (Ali, 2015).

\section{CASE STUDY}

A newly established glass factory which has 1000 employees, annual return between $100.000 €$ and $200.000 €, 15.000 \mathrm{~m}^{2}$ and located in GOSB (One of the biggest industrial zones in Istanbul), decided to purchase BPM software in order to do away with inefficiencies, better customer relations, employee satisfaction and waste-time reduction. The implementation of a software application should ensure standardization and greater efficiency of the process, as well as providing the unique and standard technology and method of operation. For this purpose, criteria were determined by the company's employees for the selection of BPM software that best fits the company's wishes. In this case a hybrid method is used which includes: NGT, Delphi, and MCDM.

\section{Determining the Initial Criteria List (Nominal Group Technique: NGT)}

In this step the group tried to eliminate the less important criteria from the list in order to make a more affective decision. A newly established glass factory has an expert team of four people. These four people's positions are sales manager, finance manager, production manager, and research and development manager. While determining our criteria, at first the nominal group technique is used. Using the NGT method, this expert team rated the selection criteria according to their own opinions. After all group members made the necessary literature research on the subject, the NGT steps are applied. First, group members determined their criterion ideas individually. The generated ideas were opened for discussion to be interpreted and explained within the group. Similar and complementary ideas were combined. After the ideas were evaluated, a list of criteria was prepared.

The criteria selected by the employees are:

- Fit with business process type: When the company decided to get BPM software, the company should take into consideration that the software must fit the company's business processes. There are two situations; either the company adapts their processes to the software or vice versa. No matter which, the company should choose the most profitable option.

- Integration \& Workflow management: The software should be suitable for the use of many business operations and departments within the company. Inputs of different departments must be integrated into each other through the software. Another benefit of the software for business process management is that by incorporating communication between workers, processes, and data sets, it helps you to create, simulate and execute advanced workflows. It also is a software that offers the opportunity to work with other applications, such as the ones that include cloud-based SaaS (Service as Software) software or onpremises software, and systems.

- Optimization of the business process: The software for business process management greatly reduces the time it takes to discover and optimize company activities to deliver better company performance. 
Employees should not waste time when using the software and perform transaction inputs through the software as quickly as possible.

- Analytics \& Analysis: In order to provide insights into the most critical business-dependent variables, business process management software may integrate prescriptive or predictive analysis. The selected BPM software should be suitable for the analysis programs, such as SPSS Statistics, Kaizen, R, or Six Sigma, used in the company. The data scientists and the analysists objective are to simplify the manufacturing /service processes in the company. The software should be adaptable for these processes and automate them as well. The company can get rid of redundant actions and processes that cause time loss with the help of the software. Afterwards, the managers can rearrange these processes.

- Flexibility: BPM software should be suitable for sharing and reusing. Employees of different departments in the company should be able to share information between each other. The software should also be sensitive to the operational and managerial changes. Regardless of any process change within the organization, the software must allow data to be changed by the employees.

- Usability \& Easiness: The BPM software that the company selects should be usable by each associated person. It should be easy to understand for everyone from the manager to the blue collar worker. For instance, the Drag and Drop feature provides a simple interface that allows you, without writing a single line of code, to design functional forms. The software should be connected to other software as quickly as possible. Because if it takes too much time to connect, all the associated works depending on this software will be delayed. This costs the company a lot of time loss and this waste of time is not easily recovered. The software must be easy to use.

- Governance \& Management: The BPM software must be auditable. The software should be traceable about what data is being produced in this company or who is recording these data from. The management can observe the employees according to sales if it is a sales company or according to customer relations if it is a service company. Therefore, the management can make some improvements about the processes or the employees. The software should ease the management's observation.

- Content management: BPM software provides collaboration, brainstorming, and the exchange of the opinions within the company. In general, companies have a hard time obtaining the required information about the current business processes, and where their teams are at the moment. It is crucial for companies to reach their teams at any given time and get process information about their whereabouts. This can be accomplished with ERP systems and also the BPM software. Teams can change, save, and share this process information with the URL at any location that has an internet connection.

- Technology: The BPM software should have an equal technology level as the company's current programs and tools. It should also have an equal technology level with the company's suppliers and collaborators to execute the common processes properly. Technology level of the selected BPM software must be much better than what the competitors' use in order to be successful in the market and be innovative in industry. As long as the company grows the need for higher technology software, like BPM software, will increase.

- Cost: These kinds of software are used in order to minimize cost and time. Unfortunately, this type software's are expensive to install and implement. If the company chooses the best software for itself, then they can use the software for years to come and eventually the software will pay off the initial investment cost. But if the wrong choice is made, then the company must face its financial results. Cost is a critical criterion of the selection of the BPM software, but it is not the only criteria when it comes to BPM software selection.

- Value out of the box: In line with the company's wishes, the BPM software should offer a desired feature easily, without requiring any additional effort, extra configuration, adaptation, or development. The software that provides this feature becomes more profitable and less of a hassle for the company.

- Long-term cycle: Since purchasing a software requires high investment for a company, the purchased software must be suitable for long-term use. Software should be able to process long-term business processes and keep them in memory. In addition, the software should provide easy access to historical data.

- Level of documentation: The language and process documentation of the software should be intelligible and explanatory for all employees who will use the software. In addition, the software should be able to answer any question the employees might have regarding the usage of the software through the manuals that come along with it.

- Feasibility and Automation: Business processes performed within the organization should be suitable for the use of the software and should be easily automated by using the software. Also, the software should be supported by the main enterprise information system of the company.

- Security: The software should be resistant to corruption and should be able to protect data against any outside threat. 
- Sensibility of external environment: The number of environmental effects on the business process depends on the many changes in laws and regulations. The right BPM software must be able to keep up with the changes.

After several discussions in the second round, employees also emphasized some additional features for the BPM software selection. The following are these emphasized features:

- Comprehensive reporting: It should provide a comprehensive report on various business processes, combining logic and statistics.

- Simulation: After modelling a business process to give an idea of what each participant will see, the user should be able to simulate the process with the simulation feature.

- Role-based routing: The BPM software should include organizational structures to enable the user to specify the role of every individual in the organization in case they are not already defined in another database.

- To-do widgets: Each employee should be able to create a list of significant to-do tasks with the business process management software and set a reminder for each task.

- Process mapping \& Real time monitoring: It should allow the company to represent ideas and business processes with flowcharts, maps, graphs, and other visuals. The software for the management of business processes should enable the company to track company's business processes in real time and to assess the output of key business indicators.

- Mobile support: Business process management software should have the ability to set up personalized work environments that employees can access from their mobile devices with customizable dashboards.

- Project management: BPM's one of the major utilities should be Performance Management, but this utility differs widely between products. This feature should enable the user to handle his/her business ventures reasonably easy.

The set of criteria list with their references is shown in Table 1.

Table 1: The Criteria List

\begin{tabular}{|l|l|l|}
\hline Criteria & Resource & Round \\
\hline Fit with business process type & (BPM Institute, 2016) & 1 \\
\hline Integration\&Workflow Management & (PAT Research, 2018) & 1 \\
\hline Business process Optimization & (BPM Institute, 2016) & 1 \\
\hline Analytics \& Analysis & (Ma, Kim, Seo, Leem, \& Moon, 2012) & 1 \\
\hline Flexibility & (Ma, Kim, Seo, Leem, \& Moon, 2012) & 1 \\
\hline Usability \& Easiness & (Kohlenbach, 2018) & 1 \\
\hline Governance & (Kohlenbach, 2018) & 1 \\
\hline Content Management & (Kohlenbach, 2018) & 1 \\
\hline Technology & (Kohlenbach, 2018) & 1 \\
\hline Cost & (Kohlenbach, 2018) & 1 \\
\hline Value out of the box & (BPM Institute, 2016) & 1 \\
\hline Long-term cycle & (Kim, Baek, Lee, \& Lim, 2018) & 1 \\
\hline Level of Documentation & (Ma, Kim, Seo, Leem, \& Moon, 2012) & 1 \\
\hline Feasibility and Automation & (Ma, Kim, Seo, Leem, \& Moon, 2012) & 1 \\
\hline Security & (Kim, Baek, Lee, \& Lim, 2018) & 1 \\
\hline Sensibility of external environment & (Kim, Baek, Lee, \& Lim, 2018) & 1 \\
\hline Comprehensive Reporting & (PAT Research, 2018) & 2 \\
\hline Simulation & (PAT Research, 2018) & 2 \\
\hline Role-based routing & (PAT Research, 2018) & 2 \\
\hline To-do widgets & (PAT Research, 2018) & 2 \\
\hline Process Mapping \& Real time monitoring & (PAT Research, 2018) \\
\hline Mobile Support & (PAT Research, 2018) & 2 \\
\hline Project Management & (PAT Research, 2018) & 2 \\
\hline
\end{tabular}

Then, all criteria were scored from 1 to 5 by each group member. The given scores were added up, averaged, and the criteria were selected. A final discussion was held for the selected criteria and the steps taken were reported. 
Table 2: The Results of NGT

\begin{tabular}{|c|c|c|c|c|c|}
\hline Topic & $\begin{array}{c}\text { Manager 1's } \\
\text { Points }\end{array}$ & $\begin{array}{c}\text { Manager 2's } \\
\text { Points }\end{array}$ & $\begin{array}{c}\text { Manager 3's } \\
\text { Points } \\
\end{array}$ & $\begin{array}{c}\text { Manager 4's } \\
\text { Points }\end{array}$ & Mean \\
\hline Fit with business process type & 4 & 4 & 5 & 5 & 4.5 \\
\hline Integration \& Workflow Management & 5 & 5 & 5 & 5 & 5 \\
\hline Business process optimization & 5 & 4 & 5 & 5 & 4.75 \\
\hline Analytics \& Analysis & 4 & 5 & 5 & 4 & 4.5 \\
\hline Flexibility & 4 & 5 & 5 & 4 & 4.5 \\
\hline Usability \& Easiness & 5 & 4 & 4 & 5 & 4.5 \\
\hline Governance* & 3 & 3 & 3 & 3 & 3 \\
\hline Content management & 4 & 4 & 4 & 4 & 4 \\
\hline Technology & 4 & 4 & 5 & 5 & 4.5 \\
\hline Cost* & 3 & 4 & 4 & 4 & 3.75 \\
\hline Value out of the box & 5 & 3 & 5 & 3 & 4 \\
\hline Long-term cycle & 4 & 4 & 5 & 4 & 4.25 \\
\hline Level of documentation* & 3 & 3 & 3 & 3 & 3 \\
\hline Feasibility and Automation & 4 & 5 & 5 & 4 & 4.5 \\
\hline Security & 5 & 5 & 5 & 5 & 5 \\
\hline Sensibility of external environment* & 2 & 3 & 3 & 3 & 2.75 \\
\hline Comprehensive reporting* & 4 & 2 & 3 & 3 & 3 \\
\hline Simulation & 3 & 4 & 5 & 5 & 4.25 \\
\hline Role-based routing* & 2 & 3 & 2 & 3 & 2.5 \\
\hline To-do widgets* & 2 & 3 & 2 & 2 & 2.25 \\
\hline Process mapping \& Real time monitoring & 5 & 4 & 5 & 5 & 4.75 \\
\hline Mobile support* & 2 & 2 & 2 & 2 & 2 \\
\hline Project management* & 3 & 3 & 3 & 3 & 3 \\
\hline
\end{tabular}

The NGT method used and scored the criteria. Then it is found their mean value as 3.84. It is eliminated criteria that were under the mean value (Taylan, 2011). So, it is obtained 14 criteria (in Table 2 with a * mark) that reduced from 23 criteria with the NGT method.

\section{Delphi Method}

The Delphi method applied to the criteria that reduced from 23 to 14 with the NGT method. A survey was prepared out of the 14 selected criteria. This survey shared with a team of employees consisting of 50 people. In the survey, it is asked the participants to score the 14 criteria between 1 and 5 based on the degree of significance. Then the averages of the data took, collected and analyzed. After reviewing the survey results, the results of participants sent back to them. The participants to be asked to review their results and fill out the survey again. For the second time, the survey took and analyzed the averages of the data that collected from the participants. The eliminated criteria with mean value is below of 4.49 , thus reduced the number of criteria to 8 .

The following are the questions of the survey: 
Journal of Global Strategic Management | V. 15 | N. 2 | 2021-December| isma.info | 107-131 | DOI: 10.20460/JGSM.2022.306

Table 3: The Survey - Criterion Selection Evaluation of BPM Software

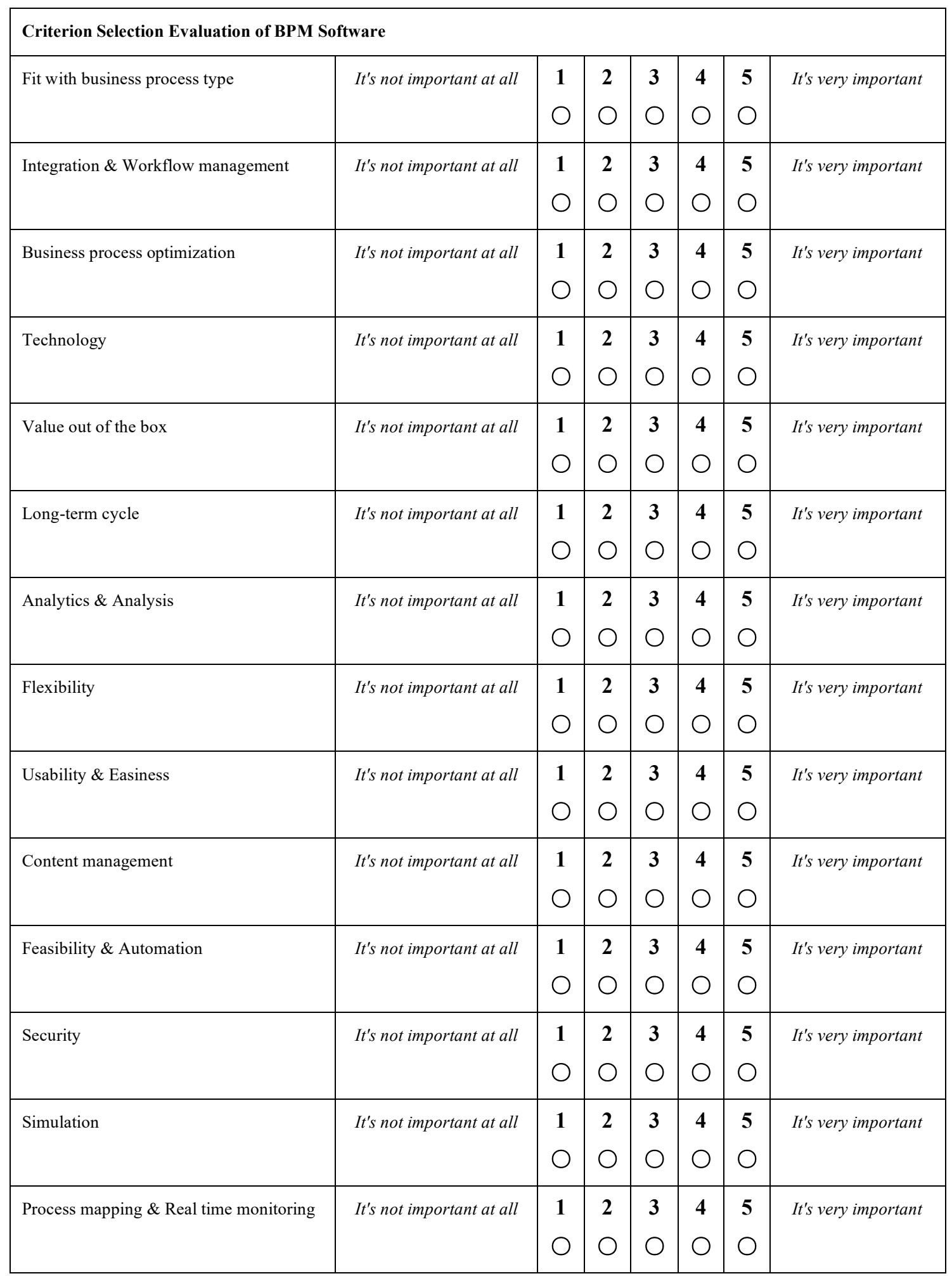

The following Figure 2 and Figure 3 represents the percentage of some of the answers of 50 participants: 


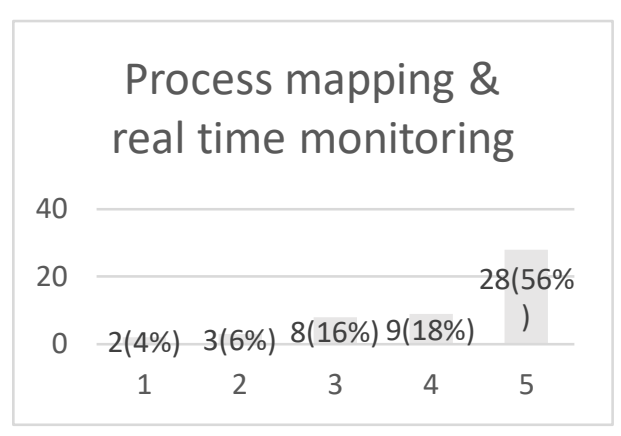
Mapping \& Real Time Monitoring Criteria

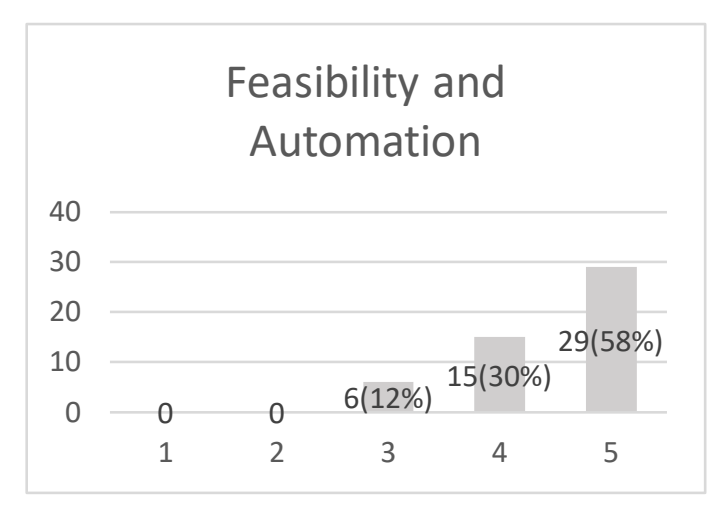

Figure 3: Percentage of the Results of Feasibility Criteria
Automation

The results of the first survey that conducted are given in Table 4 . 
Journal of Global Strategic Management | V. 15 | N. 2 | 2021-December| isma.info | 107-131 | DOI: 10.20460/JGSM.2022.306

Table 4: Results of the First Survey

\begin{tabular}{|c|c|c|c|c|c|c|c|c|c|c|c|c|c|c|}
\hline & 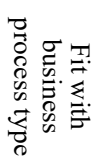 & 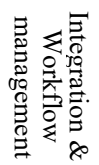 & 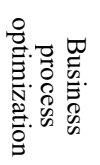 & 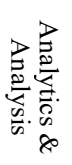 & 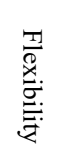 & 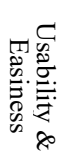 & 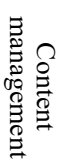 & 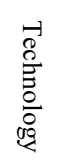 & 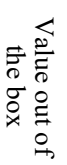 & $\begin{array}{rl} & 5 \\
2 & 0 \\
2 & 0 \\
0 & 0 \\
0 & 0 \\
0 & 0 \\
0 & 0\end{array}$ & 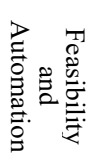 & 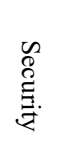 & 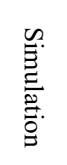 & 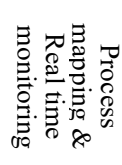 \\
\hline \multirow{50}{*}{ 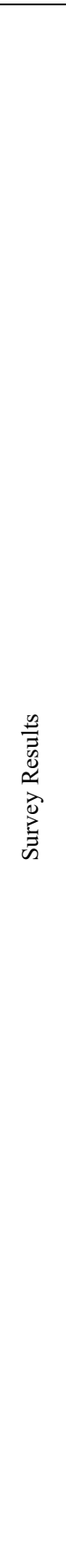 } & 4 & 5 & 5 & 5 & 4 & 3 & 4 & 4 & 5 & 3 & 5 & 5 & 3 & 2 \\
\hline & 4 & 5 & 3 & 4 & 5 & 5 & 5 & 5 & 4 & 5 & 4 & 5 & 2 & 4 \\
\hline & 5 & 5 & 5 & 5 & 5 & 5 & 5 & 5 & 5 & 5 & 5 & 5 & 5 & 5 \\
\hline & 5 & 4 & 4 & 5 & 4 & 5 & 4 & 5 & 4 & 4 & 5 & 5 & 4 & 2 \\
\hline & 5 & 5 & 5 & 4 & 5 & 5 & 5 & 1 & 4 & 5 & 5 & 5 & 4 & 5 \\
\hline & 5 & 5 & 4 & 4 & 3 & 5 & 4 & 5 & 3 & 3 & 5 & 5 & 5 & 5 \\
\hline & 5 & 5 & 5 & 4 & 5 & 5 & 5 & 5 & 5 & 5 & 5 & 5 & 5 & 5 \\
\hline & 4 & 5 & 4 & 3 & 4 & 5 & 4 & 4 & 4 & 2 & 3 & 5 & 4 & 3 \\
\hline & 5 & 5 & 5 & 5 & 5 & 5 & 5 & 5 & 5 & 5 & 5 & 5 & 5 & 5 \\
\hline & 5 & 4 & 5 & 4 & 3 & 5 & 4 & 4 & 5 & 3 & 5 & 3 & 3 & 3 \\
\hline & 4 & 3 & 5 & 4 & 5 & 5 & 4 & 2 & 4 & 3 & 3 & 5 & 3 & 5 \\
\hline & 5 & 4 & 4 & 4 & 5 & 5 & 5 & 4 & 5 & 5 & 4 & 5 & 5 & 3 \\
\hline & 4 & 5 & 5 & 5 & 5 & 5 & 5 & 5 & 5 & 5 & 5 & 5 & 5 & 5 \\
\hline & 4 & 5 & 5 & 5 & 5 & 3 & 5 & 4 & 5 & 5 & 4 & 4 & 5 & 5 \\
\hline & 5 & 4 & 5 & 4 & 4 & 5 & 5 & 4 & 5 & 4 & 5 & 5 & 4 & 4 \\
\hline & 5 & 5 & 5 & 5 & 5 & 5 & 5 & 5 & 5 & 5 & 5 & 5 & 5 & 5 \\
\hline & 5 & 5 & 5 & 5 & 5 & 5 & 5 & 4 & 5 & 4 & 4 & 5 & 5 & 4 \\
\hline & 4 & 5 & 4 & 3 & 4 & 3 & 4 & 5 & 4 & 5 & 4 & 5 & 5 & 5 \\
\hline & 5 & 5 & 5 & 5 & 5 & 5 & 5 & 5 & 4 & 4 & 4 & 5 & 4 & 4 \\
\hline & 5 & 5 & 5 & 5 & 5 & 5 & 5 & 5 & 5 & 5 & 5 & 5 & 4 & 4 \\
\hline & 5 & 5 & 5 & 4 & 4 & 5 & 5 & 3 & 3 & 5 & 5 & 5 & 4 & 5 \\
\hline & 5 & 5 & 4 & 4 & 4 & 4 & 4 & 3 & 5 & 4 & 3 & 5 & 5 & 5 \\
\hline & 4 & 5 & 4 & 4 & 4 & 4 & 4 & 5 & 4 & 4 & 4 & 5 & 5 & 5 \\
\hline & 5 & 5 & 4 & 4 & 3 & 3 & 4 & 4 & 5 & 4 & 5 & 3 & 2 & 3 \\
\hline & 5 & 5 & 5 & 4 & 5 & 4 & 4 & 4 & 5 & 4 & 4 & 5 & 5 & 5 \\
\hline & 5 & 5 & 5 & 5 & 5 & 5 & 5 & 5 & 5 & 5 & 5 & 5 & 5 & 5 \\
\hline & 5 & 5 & 5 & 5 & 5 & 5 & 5 & 5 & 5 & 5 & 5 & 5 & 4 & 4 \\
\hline & 5 & 5 & 5 & 5 & 5 & 5 & 5 & 5 & 5 & 5 & 4 & 5 & 5 & 5 \\
\hline & 5 & 4 & 4 & 4 & 5 & 4 & 4 & 4 & 4 & 4 & 4 & 5 & 4 & 5 \\
\hline & 5 & 5 & 5 & 4 & 5 & 5 & 4 & 5 & 5 & 3 & 3 & 5 & 4 & 5 \\
\hline & 5 & 4 & 3 & 4 & 3 & 2 & 5 & 5 & 4 & 3 & 3 & 5 & 3 & 2 \\
\hline & 5 & 5 & 5 & 5 & 5 & 5 & 5 & 5 & 5 & 5 & 5 & 5 & 5 & 5 \\
\hline & 5 & 5 & 4 & 5 & 5 & 3 & 5 & 5 & 4 & 5 & 4 & 4 & 5 & 5 \\
\hline & 5 & 5 & 5 & 5 & 5 & 5 & 5 & 5 & 5 & 5 & 5 & 5 & 4 & 5 \\
\hline & 4 & 5 & 4 & 5 & 5 & 4 & 4 & 4 & 5 & 5 & 5 & 5 & 3 & 4 \\
\hline & 5 & 5 & 5 & 5 & 5 & 5 & 5 & 5 & 5 & 5 & 5 & 5 & 5 & 5 \\
\hline & 5 & 5 & 5 & 5 & 5 & 3 & 5 & 5 & 5 & 5 & 5 & 5 & 3 & 3 \\
\hline & 5 & 5 & 5 & 5 & 5 & 5 & 4 & 5 & 5 & 5 & 5 & 5 & 5 & 5 \\
\hline & 5 & 5 & 5 & 5 & 5 & 5 & 5 & 5 & 5 & 4 & 5 & 5 & 5 & 5 \\
\hline & 4 & 3 & 5 & 5 & 4 & 3 & 4 & 3 & 2 & 1 & 4 & 5 & 2 & 1 \\
\hline & 5 & 5 & 5 & 5 & 5 & 5 & 5 & 5 & 5 & 3 & 5 & 5 & 5 & 5 \\
\hline & 4 & 4 & 4 & 5 & 3 & 3 & 4 & 5 & 4 & 4 & 3 & 5 & 4 & 3 \\
\hline & 5 & 4 & 3 & 5 & 5 & 3 & 3 & 1 & 5 & 5 & 4 & 5 & 5 & 4 \\
\hline & 5 & 5 & 5 & 5 & 5 & 5 & 5 & 5 & 5 & 5 & 1 & 5 & 5 & 2 \\
\hline & 4 & 4 & 5 & 5 & 5 & 5 & 5 & 5 & 5 & 5 & 5 & 5 & 5 & 5 \\
\hline & 5 & 5 & 5 & 5 & 5 & 3 & 5 & 5 & 5 & 5 & 5 & 5 & 5 & 3 \\
\hline & 4 & 4 & 4 & 4 & 4 & 4 & 4 & 4 & 4 & 4 & 4 & 4 & 4 & 4 \\
\hline & 4 & 4 & 4 & 5 & 5 & 4 & 5 & 5 & 3 & 3 & 5 & 4 & 5 & 5 \\
\hline & 5 & 5 & 5 & 5 & 5 & 5 & 5 & 5 & 5 & 5 & 5 & 5 & 5 & 5 \\
\hline & 5 & 5 & 4 & 2 & 3 & 4 & 5 & 5 & 5 & 3 & 4 & 5 & 2 & 3 \\
\hline Mean & 4.72 & 4.7 & 4.58 & 4.52 & 4.56 & 4.38 & 4.6 & 4.42 & 4.56 & 4.26 & 4.38 & 4.84 & 4.26 & 4.18 \\
\hline
\end{tabular}

The results of the second survey that conducted are given in Table 5 . 
Journal of Global Strategic Management | V. 15 | N. 2 | 2021-December| isma.info | 107-131 | DOI: 10.20460/JGSM.2022.306

Table 5: Results of the Second Survey

\begin{tabular}{|c|c|c|c|c|c|c|c|c|c|c|c|c|c|c|}
\hline & 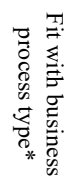 & 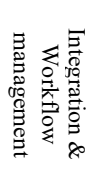 & 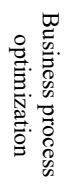 & 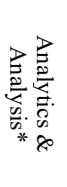 & 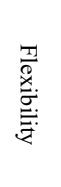 & 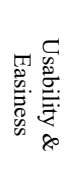 & 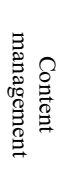 & 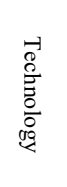 & 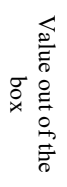 & 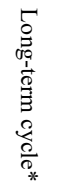 & 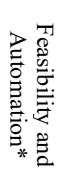 & 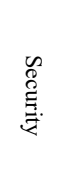 & 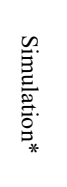 & 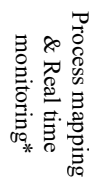 \\
\hline \multirow{50}{*}{ 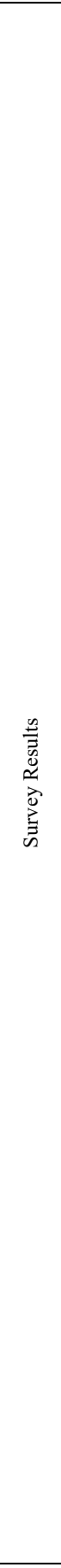 } & 4 & 5 & 5 & 5 & 4 & 3 & 4 & 4 & 5 & 3 & 5 & 5 & 3 & 2 \\
\hline & 4 & 5 & 3 & 4 & 5 & 5 & 5 & 5 & 4 & 5 & 4 & 5 & 2 & 4 \\
\hline & 5 & 5 & 5 & 5 & 5 & 5 & 5 & 5 & 5 & 5 & 5 & 5 & 5 & 5 \\
\hline & 5 & 4 & 4 & 5 & 4 & 5 & 4 & 5 & 4 & 4 & 5 & 5 & 4 & 2 \\
\hline & 5 & 5 & 5 & 4 & 5 & 5 & 5 & 1 & 4 & 5 & 5 & 5 & 4 & 5 \\
\hline & 5 & 5 & 4 & 4 & 3 & 5 & 4 & 5 & 3 & 3 & 5 & 5 & 5 & 5 \\
\hline & 5 & 5 & 5 & 4 & 5 & 5 & 5 & 5 & 5 & 5 & 5 & 5 & 4 & 5 \\
\hline & 4 & 5 & 4 & 3 & 4 & 5 & 4 & 4 & 4 & 3 & 4 & 5 & 4 & 3 \\
\hline & 5 & 5 & 5 & 5 & 5 & 5 & 5 & 5 & 5 & 5 & 5 & 5 & 5 & 5 \\
\hline & 5 & 4 & 5 & 4 & 3 & 5 & 4 & 4 & 5 & 3 & 5 & 3 & 3 & 3 \\
\hline & 4 & 3 & 5 & 4 & 5 & 5 & 4 & 2 & 4 & 3 & 3 & 5 & 3 & 5 \\
\hline & 5 & 4 & 4 & 4 & 5 & 5 & 5 & 4 & 5 & 5 & 4 & 5 & 5 & 3 \\
\hline & 4 & 5 & 5 & 5 & 5 & 5 & 5 & 5 & 5 & 5 & 5 & 5 & 5 & 4 \\
\hline & 4 & 5 & 5 & 5 & 5 & 3 & 5 & 4 & 5 & 5 & 4 & 4 & 5 & 4 \\
\hline & 5 & 4 & 5 & 4 & 4 & 5 & 5 & 4 & 5 & 4 & 5 & 5 & 4 & 4 \\
\hline & 5 & 5 & 5 & 5 & 5 & 5 & 5 & 5 & 5 & 5 & 5 & 5 & 5 & 5 \\
\hline & 5 & 5 & 5 & 5 & 5 & 5 & 5 & 4 & 5 & 4 & 4 & 5 & 5 & 4 \\
\hline & 4 & 5 & 4 & 3 & 4 & 3 & 4 & 5 & 4 & 5 & 4 & 5 & 5 & 4 \\
\hline & 5 & 5 & 5 & 5 & 5 & 5 & 5 & 5 & 4 & 4 & 4 & 5 & 4 & 4 \\
\hline & 5 & 5 & 5 & 5 & 5 & 5 & 5 & 5 & 5 & 5 & 5 & 5 & 4 & 4 \\
\hline & 5 & 5 & 5 & 4 & 4 & 5 & 5 & 3 & 3 & 5 & 5 & 5 & 4 & 5 \\
\hline & 5 & 5 & 4 & 4 & 4 & 4 & 4 & 3 & 5 & 4 & 3 & 5 & 5 & 5 \\
\hline & 5 & 5 & 4 & 4 & 4 & 4 & 4 & 5 & 4 & 4 & 4 & 5 & 5 & 5 \\
\hline & 5 & 5 & 4 & 4 & 3 & 3 & 4 & 4 & 5 & 4 & 5 & 3 & 2 & 3 \\
\hline & 5 & 5 & 5 & 4 & 5 & 4 & 4 & 4 & 5 & 4 & 4 & 5 & 5 & 4 \\
\hline & 5 & 5 & 5 & 5 & 5 & 5 & 5 & 5 & 5 & 5 & 5 & 5 & 5 & 4 \\
\hline & 5 & 5 & 5 & 5 & 5 & 5 & 5 & 5 & 5 & 5 & 5 & 5 & 3 & 4 \\
\hline & 5 & 5 & 5 & 5 & 5 & 5 & 5 & 5 & 5 & 5 & 4 & 5 & 5 & 5 \\
\hline & 5 & 4 & 4 & 4 & 5 & 4 & 4 & 4 & 4 & 4 & 4 & 5 & 4 & 5 \\
\hline & 5 & 5 & 5 & 4 & 5 & 5 & 4 & 5 & 5 & 3 & 3 & 5 & 4 & 5 \\
\hline & 5 & 4 & 3 & 4 & 3 & 2 & 5 & 5 & 4 & 3 & 3 & 5 & 3 & 2 \\
\hline & 5 & 5 & 5 & 5 & 5 & 5 & 5 & 5 & 5 & 5 & 5 & 5 & 5 & 5 \\
\hline & 5 & 5 & 4 & 5 & 5 & 3 & 5 & 5 & 4 & 5 & 4 & 4 & 5 & 5 \\
\hline & 5 & 5 & 5 & 5 & 5 & 5 & 5 & 5 & 5 & 5 & 5 & 5 & 4 & 5 \\
\hline & 4 & 5 & 4 & 5 & 5 & 4 & 4 & 4 & 5 & 5 & 5 & 5 & 3 & 3 \\
\hline & 5 & 5 & 5 & 5 & 5 & 5 & 5 & 5 & 5 & 5 & 5 & 5 & 5 & 5 \\
\hline & 5 & 5 & 5 & 5 & 5 & 3 & 5 & 5 & 5 & 5 & 5 & 5 & 3 & 3 \\
\hline & 5 & 5 & 5 & 5 & 5 & 5 & 4 & 5 & 5 & 5 & 5 & 5 & 5 & 5 \\
\hline & 5 & 5 & 5 & 5 & 5 & 5 & 5 & 5 & 5 & 4 & 5 & 5 & 5 & 5 \\
\hline & 4 & 3 & 5 & 5 & 4 & 3 & 4 & 3 & 2 & 3 & 4 & 5 & 2 & 1 \\
\hline & 5 & 5 & 5 & 5 & 5 & 5 & 5 & 5 & 5 & 3 & 5 & 5 & 5 & 5 \\
\hline & 4 & 4 & 4 & 5 & 3 & 3 & 4 & 5 & 4 & 4 & 3 & 5 & 4 & 3 \\
\hline & 5 & 4 & 3 & 5 & 5 & 3 & 3 & 1 & 5 & 5 & 4 & 5 & 5 & 3 \\
\hline & 5 & 5 & 5 & 5 & 5 & 5 & 5 & 5 & 5 & 5 & 3 & 5 & 5 & 2 \\
\hline & 4 & 4 & 5 & 4 & 5 & 5 & 5 & 5 & 5 & 5 & 5 & 5 & 5 & 5 \\
\hline & 5 & 5 & 5 & 5 & 5 & 3 & 5 & 5 & 5 & 5 & 5 & 5 & 5 & 3 \\
\hline & 4 & 4 & 4 & 4 & 4 & 4 & 4 & 4 & 4 & 4 & 4 & 4 & 4 & 4 \\
\hline & 5 & 4 & 4 & 5 & 5 & 4 & 5 & 5 & 3 & 3 & 5 & 4 & 5 & 3 \\
\hline & 5 & 5 & 5 & 4 & 5 & 5 & 5 & 5 & 5 & 5 & 5 & 5 & 5 & 5 \\
\hline & 5 & 5 & 4 & 3 & 3 & 4 & 5 & 5 & 5 & 3 & 4 & 5 & 2 & 3 \\
\hline Mean & 4.76 & 4.70 & 4.58 & 4.50 & 4.56 & 4.38 & 4.60 & 4.42 & 4.56 & 4.32 & 4.44 & 4.84 & 4.22 & 4.00 \\
\hline
\end{tabular}

In the table above, criteria marked as “*” are those of the participants who changed their opinions. 
Table 6: Eliminated Results of the Second Survey

\begin{tabular}{|c|c|c|c|c|c|c|c|c|c|c|c|c|c|c|}
\hline & 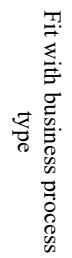 & 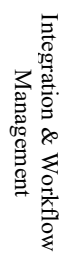 & 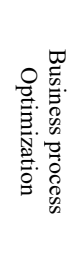 & 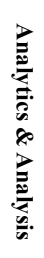 & 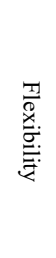 & 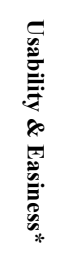 & 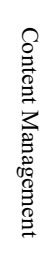 & 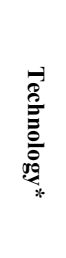 & 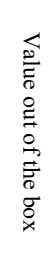 & 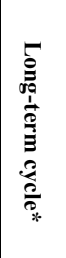 & 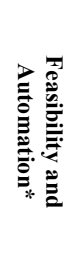 & 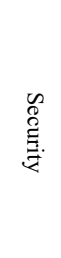 & 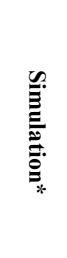 & 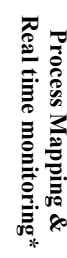 \\
\hline \multirow{50}{*}{ 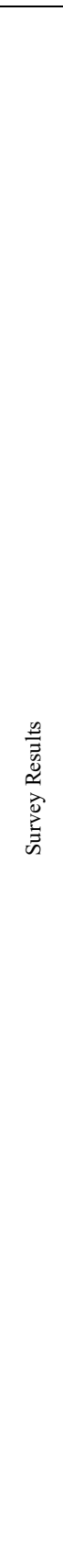 } & 4 & 5 & 5 & 5 & 4 & 3 & 4 & 4 & 5 & 3 & 5 & 5 & 3 & 2 \\
\hline & 4 & 5 & 3 & 4 & 5 & 5 & 5 & 5 & 4 & 5 & 4 & 5 & 2 & 4 \\
\hline & 5 & 5 & 5 & 5 & 5 & 5 & 5 & 5 & 5 & 5 & 5 & 5 & 5 & 5 \\
\hline & 5 & 4 & 4 & 5 & 4 & 5 & 4 & 5 & 4 & 4 & 5 & 5 & 4 & 2 \\
\hline & 5 & 5 & 5 & 4 & 5 & 5 & 5 & 1 & 4 & 5 & 5 & 5 & 4 & 5 \\
\hline & 5 & 5 & 4 & 4 & 3 & 5 & 4 & 5 & 3 & 3 & 5 & 5 & 5 & 5 \\
\hline & 5 & 5 & 5 & 4 & 5 & 5 & 5 & 5 & 5 & 5 & 5 & 5 & 4 & 5 \\
\hline & 4 & 5 & 4 & 3 & 4 & 5 & 4 & 4 & 4 & 3 & 4 & 5 & 4 & 3 \\
\hline & 5 & 5 & 5 & 5 & 5 & 5 & 5 & 5 & 5 & 5 & 5 & 5 & 5 & 5 \\
\hline & 5 & 4 & 5 & 4 & 3 & 5 & 4 & 4 & 5 & 3 & 5 & 3 & 3 & 3 \\
\hline & 4 & 3 & 5 & 4 & 5 & 5 & 4 & 2 & 4 & 3 & 3 & 5 & 3 & 5 \\
\hline & 5 & 4 & 4 & 4 & 5 & 5 & 5 & 4 & 5 & 5 & 4 & 5 & 5 & 3 \\
\hline & 4 & 5 & 5 & 5 & 5 & 5 & 5 & 5 & 5 & 5 & 5 & 5 & 5 & 4 \\
\hline & 4 & 5 & 5 & 5 & 5 & 3 & 5 & 4 & 5 & 5 & 4 & 4 & 5 & 4 \\
\hline & 5 & 4 & 5 & 4 & 4 & 5 & 5 & 4 & 5 & 4 & 5 & 5 & 4 & 4 \\
\hline & 5 & 5 & 5 & 5 & 5 & 5 & 5 & 5 & 5 & 5 & 5 & 5 & 5 & 5 \\
\hline & 5 & 5 & 5 & 5 & 5 & 5 & 5 & 4 & 5 & 4 & 4 & 5 & 5 & 4 \\
\hline & 4 & 5 & 4 & 3 & 4 & 3 & 4 & 5 & 4 & 5 & 4 & 5 & 5 & 4 \\
\hline & 5 & 5 & 5 & 5 & 5 & 5 & 5 & 5 & 4 & 4 & 4 & 5 & 4 & 4 \\
\hline & 5 & 5 & 5 & 5 & 5 & 5 & 5 & 5 & 5 & 5 & 5 & 5 & 4 & 4 \\
\hline & 5 & 5 & 5 & 4 & 4 & 5 & 5 & 3 & 3 & 5 & 5 & 5 & 4 & 5 \\
\hline & 5 & 5 & 4 & 4 & 4 & 4 & 4 & 3 & 5 & 4 & 3 & 5 & 5 & 5 \\
\hline & 5 & 5 & 4 & 4 & 4 & 4 & 4 & 5 & 4 & 4 & 4 & 5 & 5 & 5 \\
\hline & 5 & 5 & 4 & 4 & 3 & 3 & 4 & 4 & 5 & 4 & 5 & 3 & 2 & 3 \\
\hline & 5 & 5 & 5 & 4 & 5 & 4 & 4 & 4 & 5 & 4 & 4 & 5 & 5 & 4 \\
\hline & 5 & 5 & 5 & 5 & 5 & 5 & 5 & 5 & 5 & 5 & 5 & 5 & 5 & 4 \\
\hline & 5 & 5 & 5 & 5 & 5 & 5 & 5 & 5 & 5 & 5 & 5 & 5 & 3 & 4 \\
\hline & 5 & 5 & 5 & 5 & 5 & 5 & 5 & 5 & 5 & 5 & 4 & 5 & 5 & 5 \\
\hline & 5 & 4 & 4 & 4 & 5 & 4 & 4 & 4 & 4 & 4 & 4 & 5 & 4 & 5 \\
\hline & 5 & 5 & 5 & 4 & 5 & 5 & 4 & 5 & 5 & 3 & 3 & 5 & 4 & 5 \\
\hline & 5 & 4 & 3 & 4 & 3 & 2 & 5 & 5 & 4 & 3 & 3 & 5 & 3 & 2 \\
\hline & 5 & 5 & 5 & 5 & 5 & 5 & 5 & 5 & 5 & 5 & 5 & 5 & 5 & 5 \\
\hline & 5 & 5 & 4 & 5 & 5 & 3 & 5 & 5 & 4 & 5 & 4 & 4 & 5 & 5 \\
\hline & 5 & 5 & 5 & 5 & 5 & 5 & 5 & 5 & 5 & 5 & 5 & 5 & 4 & 5 \\
\hline & 4 & 5 & 4 & 5 & 5 & 4 & 4 & 4 & 5 & 5 & 5 & 5 & 3 & 3 \\
\hline & 5 & 5 & 5 & 5 & 5 & 5 & 5 & 5 & 5 & 5 & 5 & 5 & 5 & 5 \\
\hline & 5 & 5 & 5 & 5 & 5 & 3 & 5 & 5 & 5 & 5 & 5 & 5 & 3 & 3 \\
\hline & 5 & 5 & 5 & 5 & 5 & 5 & 4 & 5 & 5 & 5 & 5 & 5 & 5 & 5 \\
\hline & 5 & 5 & 5 & 5 & 5 & 5 & 5 & 5 & 5 & 4 & 5 & 5 & 5 & 5 \\
\hline & 4 & 3 & 5 & 5 & 4 & 3 & 4 & 3 & 2 & 3 & 4 & 5 & 2 & 1 \\
\hline & 5 & 5 & 5 & 5 & 5 & 5 & 5 & 5 & 5 & 3 & 5 & 5 & 5 & 5 \\
\hline & 4 & 4 & 4 & 5 & 3 & 3 & 4 & 5 & 4 & 4 & 3 & 5 & 4 & 3 \\
\hline & 5 & 4 & 3 & 5 & 5 & 3 & 3 & 1 & 5 & 5 & 4 & 5 & 5 & 3 \\
\hline & 5 & 5 & 5 & 5 & 5 & 5 & 5 & 5 & 5 & 5 & 3 & 5 & 5 & 2 \\
\hline & 4 & 4 & 5 & 4 & 5 & 5 & 5 & 5 & 5 & 5 & 5 & 5 & 5 & 5 \\
\hline & 5 & 5 & 5 & 5 & 5 & 3 & 5 & 5 & 5 & 5 & 5 & 5 & 5 & 3 \\
\hline & 4 & 4 & 4 & 4 & 4 & 4 & 4 & 4 & 4 & 4 & 4 & 4 & 4 & 4 \\
\hline & 5 & 4 & 4 & 5 & 5 & 4 & 5 & 5 & 3 & 3 & 5 & 4 & 5 & 3 \\
\hline & 5 & 5 & 5 & 4 & 5 & 5 & 5 & 5 & 5 & 5 & 5 & 5 & 5 & 5 \\
\hline & 5 & 5 & 4 & 3 & 3 & 4 & 5 & 5 & 5 & 3 & 4 & 5 & 2 & 3 \\
\hline Mean & 4.76 & 4.7 & 4.58 & 4.5 & 4.56 & 4.38 & 4.6 & 4.42 & 4.56 & \begin{tabular}{|l|l|}
4.32 \\
\end{tabular} & 4.44 & 4.84 & 4.22 & 4 \\
\hline
\end{tabular}

In the above Table, the criteria that are under the mean value were eliminated (Taylan, 2011) as 4.49. Criteria marked as “*” are the criteria that were eliminated. Thus, Fit with business process type, Integration $\&$ Workflow management, Business process optimization, Flexibility, Content management, Value out of the box, Security, Analytics \& Analysis are the selected criteria. 


\section{Applying MCDM - AHP to the Criteria}

When applying AHP, at first it is organized the problem hierarchically, as in Figure 4, so that the decision making problem became more understandable.

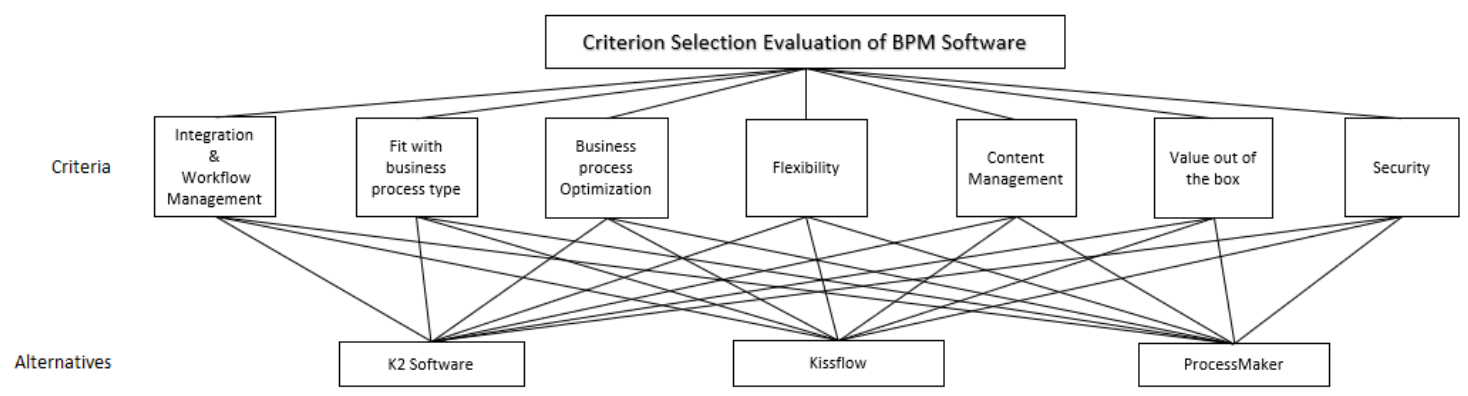

Figure 4: Criterion Selection Evaluation of BPM Software

When comparing the decision criteria, the Saaty-developed scale used that given in Table 7.

Table 7: Saaty's Scale (Ammarapala, et al., 2018)

\begin{tabular}{|c|l|l|}
\hline Intensity of Importance & Definition & Explanation \\
\hline 1 & Equal importance & $\begin{array}{l}\text { Two activities contribute equally to } \\
\text { the objective }\end{array}$ \\
\hline 3 & $\begin{array}{l}\text { Weak importance of one over } \\
\text { another }\end{array}$ & $\begin{array}{l}\text { Experience and judgment slightly favor one } \\
\text { activity over another }\end{array}$ \\
\hline 5 & Essential or strong importance & $\begin{array}{l}\text { Experience and judgment strongly favor one } \\
\text { activity over another }\end{array}$ \\
\hline 7 & Demonstrated importance & $\begin{array}{l}\text { An activity is strongly favored and its } \\
\text { dominance is demonstrated in practice }\end{array}$ \\
\hline 9 & Absolute importance & $\begin{array}{l}\text { The evidence favoring one activity over another } \\
\text { is of the highest possible order of affirmation }\end{array}$ \\
\hline $2,4,6,8$ & $\begin{array}{l}\text { Intermediate values between the } \\
\text { two adjacent judgments }\end{array}$ & When compromise is needed \\
\hline
\end{tabular}

A binary comparison matrix is created to compare the decision criteria with each other in Table 8 .

Table 8: Comparison Matrix for Main Criteria - Step 1

\begin{tabular}{|l|c|l|c|c|c|c|c|c|}
\cline { 2 - 8 } \multicolumn{1}{c|}{} & $\begin{array}{l}\text { Fit with } \\
\text { business } \\
\text { process } \\
\text { type }\end{array}$ & $\begin{array}{l}\text { Integration } \\
\text { \& Workflow } \\
\text { Management }\end{array}$ & $\begin{array}{l}\text { Business } \\
\text { process } \\
\text { Optimization }\end{array}$ & Flexibility & $\begin{array}{l}\text { Content } \\
\text { Management }\end{array}$ & $\begin{array}{l}\text { Value out } \\
\text { of the box }\end{array}$ & Security & $\begin{array}{l}\text { Analytics } \\
\text { \& Analysis }\end{array}$ \\
\begin{tabular}{|l} 
Fit with \\
business \\
process type
\end{tabular} & 1.00 & 0.33 & 0.33 & 1.00 & 0.14 & 0.14 & 0.11 & 0.33 \\
\hline $\begin{array}{l}\text { Integration } \\
\text { \& Workflow } \\
\text { Management }\end{array}$ & 3.00 & 1.00 & 3.00 & 1.00 & 0.20 & 3.00 & 0.20 & 3.00 \\
\hline $\begin{array}{l}\text { Business } \\
\text { process } \\
\text { Optimization }\end{array}$ & 3.00 & 0.33 & 1.00 & 1.00 & 0.20 & 1.00 & 0.14 & 1.00 \\
\hline Flexibility & 1.00 & 1.00 & 1.00 & 1.00 & 0.14 & 1.00 & 0.14 & 1.00 \\
\hline $\begin{array}{l}\text { Content } \\
\text { Management }\end{array}$ & 7.00 & 5.00 & 5.00 & 7.00 & 1.00 & 5.00 & 0.33 & 7.00 \\
\hline $\begin{array}{l}\text { Value out of } \\
\text { the box }\end{array}$ & 7.00 & 0.33 & 1.00 & 1.00 & 0.20 & 1.00 & 0.20 & 5.00 \\
\hline Security & 9.00 & 5.00 & 7.00 & 7.00 & 3.00 & 5.00 & 1.00 & 9.00 \\
\hline $\begin{array}{l}\text { Analytics \& } \\
\text { Analysis }\end{array}$ & 3.00 & 0.33 & 1.00 & 1.00 & 0.14 & 0.20 & 0.11 & 1.00 \\
\hline
\end{tabular}

After recreating the table so that the column totals are one, it is collected the rows and obtained the Matrix $\mathrm{W}$, which is the weight matrix. 
Journal of Global Strategic Management | V. 15 | N. 2 | 2021-December| isma.info | 107-131 | DOI: 10.20460/JGSM.2022.306

Table 9: Weighted Matrix for Main Criteria - Step 2

\begin{tabular}{|l|c|c|c|c|c|c|c|c|c|}
\cline { 2 - 10 } & $\begin{array}{c}\text { Fit with } \\
\text { business } \\
\text { process } \\
\text { type }\end{array}$ & $\begin{array}{c}\text { Integration } \\
\text { \& Workflow } \\
\text { Management }\end{array}$ & $\begin{array}{c}\text { Business } \\
\text { process } \\
\text { Optimization }\end{array}$ & Flexibility & $\begin{array}{c}\text { Content } \\
\text { Management }\end{array}$ & $\begin{array}{c}\text { Value out } \\
\text { of the box }\end{array}$ & Security & $\begin{array}{c}\text { Analytics } \\
\text { \& } \\
\text { Analysis }\end{array}$ & $\underline{\text { Matrix W }}$ \\
\hline $\begin{array}{l}\text { Fit with business } \\
\text { process type }\end{array}$ & 0.029412 & 0.025019 & 0.017072 & 0.050000 & 0.027888 & 0.008741 & 0.049801 & 0.012075 & 0.220008 \\
\hline $\begin{array}{l}\text { Integration \& } \\
\text { Workflow } \\
\text { Management }\end{array}$ & 0.088235 & 0.075056 & 0.155199 & 0.050000 & 0.039841 & 0.183566 & 0.089641 & 0.109769 & 0.791309 \\
\hline $\begin{array}{l}\text { Business process } \\
\text { Optimization }\end{array}$ & 0.088235 & 0.024769 & 0.051733 & 0.050000 & 0.039841 & 0.061189 & 0.062749 & 0.036590 & 0.415105 \\
\hline Flexibility & 0.029412 & 0.075056 & 0.051733 & 0.050000 & 0.027888 & 0.061189 & 0.062749 & 0.036590 & 0.394617 \\
\hline Content Management & 0.205882 & 0.375281 & 0.258665 & 0.350000 & 0.199203 & 0.305944 & 0.147908 & 0.256129 & 2.099014 \\
\hline Value out of the box & 0.205882 & 0.024769 & 0.051733 & 0.050000 & 0.039841 & 0.061189 & 0.089641 & 0.182949 & 0.706004 \\
\hline Security & 0.264706 & 0.375281 & 0.362131 & 0.350000 & 0.597610 & 0.305944 & 0.448207 & 0.329308 & 3.033188 \\
\hline Analytics \& Analysis & 0.088235 & 0.024769 & 0.051733 & 0.050000 & 0.027888 & 0.012238 & 0.049303 & 0.036590 & 0.340756 \\
\hline
\end{tabular}

The significance level of the criteria is determined with the Matrix W(weight) that found. According to the results obtained, the importance ranking of the criteria is as follows: Security; Content management; Integration \& Workflow management; Value of the box; Business process optimization; Flexibility; Fit with business process type; Analytics \& Analysis.

In order to determine the mathematical and logical relationship of the values obtained as a result of binary comparisons, the Consistency Ratio is calculated by following the subsequent steps:

1. The Matrix D is obtained by multiplying the Matrix $\mathrm{W}$ and the binary comparison matrix.

Table 10: Diagonal matrix for main criteria

\begin{tabular}{|l|c|}
\cline { 2 - 2 } \multicolumn{1}{c|}{} & Matrix D \\
\hline Fit with business process type & 1.859569 \\
\hline Integration \& Workflow management & 7.257984 \\
\hline Business process optimization & 3.622086 \\
\hline Flexibility & 3.586307 \\
\hline Content management & 19.349719 \\
\hline Value out of the box & 6.047130 \\
\hline Security & 27.531719 \\
\hline Analytics \& Analysis & 2.840346 \\
\hline
\end{tabular}

2. The Matrix E is created by dividing the Matrix D into the Matrix W.

Table 11: Essential Value Matrix for Criteria

\begin{tabular}{|l|c|c|c|}
\cline { 2 - 4 } \multicolumn{1}{c|}{} & Matrix D & Matrix W & $\underline{\text { Matrix E }}$ \\
\hline Fit with business process type & 1.859569 & 0.220008 & 8.452295 \\
\hline Integration \& Workflow management & 7.257984 & 0.791309 & 9.172126 \\
\hline Business process optimization & 3.622086 & 0.415105 & 8.725706 \\
\hline Flexibility & 3.586307 & 0.394617 & 9.088065 \\
\hline Content management & 19.349719 & 2.099014 & 9.218482 \\
\hline Value out of the box & 6.047130 & 0.706004 & 8.565292 \\
\hline Security & 27.531719 & 3.033188 & 9.076826 \\
\hline Analytics \& Analysis & 2.840346 & 0.340756 & 8.335431 \\
\hline
\end{tabular}

3. Taking the average of the values in Matrix E, it is obtained the result $\lambda=8.829278$.

4. The CI is calculated which is a Consistency Index.

$$
C I=(\lambda-n) /(n-1)
$$


5. The $\mathrm{CR}$ value is calculated by using the $\mathrm{CI}$ value that obtained.

Consistency Ratio $(C R)=$ Consistency Index (CI) / Random Consistency Index (RI)

Table 12: RI (Ammarapala, et al., 2018)

\begin{tabular}{|c|c|c|c|c|c|c|c|c|c|c|}
\hline Matrix Size & 1 & 2 & 3 & 4 & 5 & 6 & 7 & 8 & 9 & 10 \\
\hline Random Consistency Index (RI) & 0.00 & 0.00 & 0.58 & 0.90 & 1.12 & 1.24 & 1.32 & 1.41 & 1.45 & 1.49 \\
\hline
\end{tabular}

Based on Table 12, it is chose 1.41 as the RI value because our matrix size is 8 .

$\mathrm{CR}=0.118468 / 1,41=0.084020$

The Consistency Ratio is important for the quality and validity of the final decision. For the decision matrix to be consistent, it must be $C R<0,10$. The comparison results will be more consistent as CR approaches zero.

\section{BPM Software Alternatives}

Three different software is handled to select the best one for the criteria that obtained previously. These three software are Kissflow, K2, ProcessMaker.

Kissflow: Kissflow is one of the popular business process management software preferred by users from various industries. Kissflow is a powerful software specially designed to increase efficiency and productivity in all areas. It aims to provide convenience with the advice and solutions it offers to the user.

- No coding required.

- It adapts quickly to the changes in the process.

- It has an easy to use interface with its uncomplicated design.

- It has good reviews for the flexibility of workflows.

- Offers ready-to-use applications.

- Built for data scalability. It prevents complexities.

- Offers real-time and advanced report monitoring (Kissflow Business Process Management Software).

K2 Software: K2 software with its design, offers businesses of all sizes the opportunity to increase employee productivity, reduce broadcast errors and monitor the process as well. It aims to achieve excellence in the business process with its features.

- Connects with the data needed and integrates existing systems and tools with your application. It allows data combining.

- Reusable forms can be created.

- It integrates with many different platforms according to your needs.

- Resolves automation problems in your organization with its advanced automation feature.

- Helps you create workflows.

- It has reporting and analysis tools that allow you to make real-time reviews.

- It has been developed as a security and control tool (K2 Software).

ProcessMaker: ProcessMaker is a low-code workflow software. ProcessMaker eases the automation of complex business processes by connecting end users and existing enterprise systems, rather than business analysts having to collaborate with IT. ProcessMaker has three features to improve process optimization strategy:

1. Robust Integrations

2. Reporting Tools

3. Information Flow (3 ProcessMaker Features to Boost Your Process Optimization Strategy)

With ProcessMaker, users can create their workflow designs, and map problems more quickly. ProcessMaker enables to decrease bottlenecks, it brings digital agility to the organizations, and it helps to integrate to third party systems. (ProcessMaker)

Some features of ProcessMaker:

- Integration

- Document Management

- Workflow Automation 
- Workflow Mapping

- Logic and Conditions

- No-Code Or Low-Code

- Real-Time Process Monitoring

- Process Analysis

- Process Overview

- Process Routing

- Accessibility

- Process Design

- Document Generation

- Process Repository

- No-Code App Development

- Dashboards and KPIs (ProcessMaker Features)

\section{Applying AHP to Alternatives}

After reviewing the features of the candidate software offered by the management, it is started the elimination process. Therefore, AHP steps are applied for each feature by comparing the three software.

The software to be selected among them was compared by creating double matrices for each criterion. For each criterion, the $\mathrm{W}$ weight matrices of each software were calculated. By finding the percentages of the software with the obtained $\mathrm{W}$ matrices, the degrees of importance in each criterion were determined.

\begin{tabular}{|c|c|c|c|c|c|c|c|c|c|c|c|c|}
\hline \multicolumn{13}{|c|}{ Flexibility: } \\
\hline & \multicolumn{3}{|c|}{$\begin{array}{l}\text { Table 13: } \\
\text { Comparison } \\
\text { Matrix }\end{array}$} & \multicolumn{5}{|c|}{$\begin{array}{l}\text { Table 14: Weighted Matrix and } \\
\text { Percentages }\end{array}$} & \multirow{2}{*}{\begin{tabular}{|l|}
$\begin{array}{l}\text { Table 15: } \\
\text { Diagonal } \\
\text { Matrix }\end{array}$ \\
Matrix D \\
\end{tabular}} & \multirow{2}{*}{\begin{tabular}{|l|} 
Table 16: \\
Essential \\
Value \\
Matrix \\
\\
Matrix E
\end{tabular}} & \multicolumn{2}{|c|}{$\begin{array}{l}\text { Table 17: } \\
\text { Consistency Ratio }\end{array}$} \\
\hline & K2 & $\begin{array}{l}\text { Kiss } \\
\text { flow }\end{array}$ & $\begin{array}{l}\text { Process } \\
\text { Maker }\end{array}$ & $\mathrm{K} 2$ & $\begin{array}{l}\text { Kiss } \\
\text { flow }\end{array}$ & $\begin{array}{l}\text { Process } \\
\text { Maker }\end{array}$ & $\begin{array}{l}\text { W } \\
\text { Matrix }\end{array}$ & $\%$ & & & $\begin{array}{l}\text { Mean of } \\
\text { Matrix } \\
\text { E }\end{array}$ & 3.033227551 \\
\hline $\mathrm{K} 2$ & 1.00 & 0.33 & 0.20 & 0.11 & 0.08 & 0.13 & 0.32 & $10.60 \%$ & 0.955829673 & 3.001186409 & CI & 0.016613776 \\
\hline Kissflow & 3.00 & 1.00 & 0.33 & 0.33 & 0.23 & 0.22 & 0.78 & $26.00 \%$ & 2.361751121 & 3.031443092 & RI & 0.58 \\
\hline $\begin{array}{l}\text { Process } \\
\text { Maker }\end{array}$ & 5.00 & 3.00 & 1.00 & 0.56 & 0.69 & 0.65 & 1.90 & $63.40 \%$ & 5.832103126 & 3.178031211 & CR & 0.028644441 \\
\hline Total & 9.00 & 4.33 & $\underline{1.53}$ & & & & $\underline{3.00}$ & $100 \%$ & & & & \\
\hline
\end{tabular}

\begin{tabular}{|c|c|c|c|c|c|c|c|c|c|c|c|c|}
\hline \multicolumn{13}{|l|}{ Security: } \\
\hline & \multicolumn{3}{|c|}{$\begin{array}{l}\text { Table 18: } \\
\text { Comparison } \\
\text { Matrix }\end{array}$} & \multicolumn{5}{|c|}{$\begin{array}{l}\text { Table 19: Weighted Matrix and } \\
\text { Percentages }\end{array}$} & \multirow{2}{*}{\begin{tabular}{|l|} 
Table 20: \\
Diagonal \\
Matrix
\end{tabular}} & \multirow{2}{*}{\begin{tabular}{|l} 
Table 21: \\
Essential \\
Value \\
Matrix \\
\\
Matrix E
\end{tabular}} & \multicolumn{2}{|c|}{$\begin{array}{l}\text { Table 22: } \\
\text { Consistency Ratio }\end{array}$} \\
\hline & $\mathrm{K} 2$ & $\begin{array}{l}\text { Kiss } \\
\text { flow }\end{array}$ & $\begin{array}{l}\text { Process } \\
\text { Maker }\end{array}$ & K2 & $\begin{array}{l}\text { Kiss } \\
\text { flow }\end{array}$ & $\begin{array}{l}\text { Process } \\
\text { Maker }\end{array}$ & $\begin{array}{l}\text { W } \\
\text { Matrix }\end{array}$ & $\%$ & & & \begin{tabular}{|l} 
Mean of \\
Matrix \\
E
\end{tabular} & 3.070220238 \\
\hline $\mathrm{K} 2$ & 1.00 & 0.33 & 0.11 & 0.08 & \begin{tabular}{|l|}
0.04 \\
\end{tabular} & 0.09 & 0.20 & $6.82 \%$ & 0.613859437 & 3.005351685 & CI & 0.035110119 \\
\hline Kissflow & 3.00 & 1.00 & 0.14 & 0.23 & 0.12 & 0.11 & 0.46 & $15.43 \%$ & 1.403004156 & 3.02801614 & RI & 0.58 \\
\hline $\begin{array}{l}\text { Process } \\
\text { Maker }\end{array}$ & 9.00 & 7.00 & 1.00 & 0.69 & $\mid 0.84$ & 0.80 & 2.33 & $77.75 \%$ & 7.413214886 & 3.066314829 & CR & 0.060534688 \\
\hline Total & 13.00 & 8.33 & 1.25 & & & & 3.00 & $100.00 \%$ & & & & \\
\hline
\end{tabular}


Journal of Global Strategic Management | V. 15 | N. 2 | 2021-December| isma.info | 107-131 | DOI: 10.20460/JGSM.2022.306

\begin{tabular}{|l|l|l|r|r|r|r|r|r|r|l|l|l|}
\hline \multicolumn{2}{|l|}{ Analytics \& Analysis: } \\
\hline
\end{tabular}

\begin{tabular}{|l|l|l|l|l|l|l|l|l|l|l|l|l|}
\hline \multicolumn{2}{|l|}{ Content Management: } \\
\hline
\end{tabular}

\begin{tabular}{|l|l|l|l|l|l|l|l|l|l|l|l|l|l|}
\hline \multicolumn{2}{|l|}{ Business Process Optimization: } \\
\hline
\end{tabular}

\begin{tabular}{|l|l|l|l|l|l|l|l|l|r|l|l|l|l|}
\hline \multicolumn{2}{|l|}{ Fit with Business Process Type: } \\
\hline
\end{tabular}


Journal of Global Strategic Management | V. 15 | N. 2 | 2021-December| isma.info | 107-131 | DOI: 10.20460/JGSM.2022.306

\begin{tabular}{|l|l|l|l|l|l|l|l|l|l|l|l|}
\hline \multicolumn{2}{|l|}{ Integration \& Workflow Management: } \\
\hline
\end{tabular}

\begin{tabular}{|l|l|l|l|l|l|l|l|l|l|l|l|l|}
\hline \multicolumn{2}{|l|}{ Value Out of the Box: } \\
\hline
\end{tabular}

The degree of importance between the software was determined by multiplying the $\mathrm{W}$ weight matrix created for the criteria with these percentage values derived from the $\mathrm{W}$ weight matrices of the software. ProcessMaker is the software that must be selected based on the results obtained.

Table 53: Percentages of Criteria

\begin{tabular}{|c|c|c|c|c|c|c|c|c|}
\cline { 2 - 8 } \multicolumn{1}{c|}{} & $\begin{array}{c}\text { Fit with } \\
\text { business } \\
\text { process } \\
\text { type }\end{array}$ & $\begin{array}{c}\text { Integration \& } \\
\text { Workflow } \\
\text { Management }\end{array}$ & $\begin{array}{c}\text { Business } \\
\text { Process } \\
\text { Optimization }\end{array}$ & Flexibility & $\begin{array}{c}\text { Content } \\
\text { Management }\end{array}$ & $\begin{array}{c}\text { Value out } \\
\text { of the Box }\end{array}$ & Security & $\begin{array}{c}\text { Analytics } \\
\& \text { Analysis }\end{array}$ \\
\hline K2 & $33.33 \%$ & $18.62 \%$ & $8.25 \%$ & $10.60 \%$ & $11.50 \%$ & $14.29 \%$ & $6.82 \%$ & $8.25 \%$ \\
\hline Kissflow & $33.33 \%$ & $15.79 \%$ & $19.33 \%$ & $26.00 \%$ & $40.55 \%$ & $14.29 \%$ & $15.43 \%$ & $19.33 \%$ \\
\hline ProcessMaker & $33.33 \%$ & $65.60 \%$ & $72.42 \%$ & $63.40 \%$ & $47.96 \%$ & $71.43 \%$ & $77.75 \%$ & $72.42 \%$ \\
\hline
\end{tabular}

Table 54: Weighted Matrix of Criteria

\begin{tabular}{|c|c|c|c|c|c|c|c|c|}
\hline $\begin{array}{c}\text { W Matrix } \\
\text { of Criteria }\end{array}$ & 0.220008 & 0.791309 & 0.415105 & 0.394617 & 2.099 .014 & 0.706004 & 3.033 .188 & 0.340756 \\
\hline
\end{tabular}

Table 55: Percentages of the Software

\begin{tabular}{|l|l|l|}
\hline & $\begin{array}{l}\text { W Matrix of Criteria } \\
\text { X } \\
\text { W Matrix of Software }\end{array}$ & $\begin{array}{l}\text { Percentages of } \\
\text { Software }\end{array}$ \\
\hline K2 & 0.873821 & $10.92 \%$ \\
\hline Kissflow & 1.866880 & $23.34 \%$ \\
\hline ProcessMaker & 5.259299 & $\underline{\mathbf{6 5 . 7 4 \%}}$ \\
\hline & 8.000000 & $100.00 \%$ \\
\hline
\end{tabular}




\section{RESULTS \& FINDINGS}

The proposed model was applied in a glass manufacturing company, in a real BPM system selection case. The model is practical, easy to use and helps the decision makers to consider all the necessary aspects in evaluating the existing BPM alternatives. Afterwards, it is decided the most suitable software that fit the selected criteria from the three different software. AHP used in order to decide the best software.

The full support of experts in the company helped to use their experiences about the business processes of the company and thus eliminate the biases in the weights for BPM software alternatives. This approach can be used by experts or decision-makers, members of a cross-functional team of a company which plans to implement a BPM system.

A comprehensive list of BPM system selection 23 factors are created after an in-depth study of the literature. The number of BPM software selection criteria is reduced to 14 criteria according to the companies' experts based on the proposed model including NGT. The 14 criteria were selected because their mean value was above 3.84. The number of BPM software selection criteria is reduced to 8 criteria according to the companies' experts based on the proposed model including Delphi method. The 8 criteria were selected because their mean value were above 4.49 .

The model decomposes the evaluation of the alternatives into two stages. First, the criteria are evaluated by AHP method with respect to each main group of BPM selection factors separately. The obtained results are integrated in the second stage and the final ranking of the software alternatives is determined using AHP method.

Since it offers a separate ranking with respect to each main group of BPM selection criteria, a short list of alternatives can be achieved by eliminating the alternatives with bad scores in each evaluation area.

AHP is used to assign weights to the criteria to be used in alternative prioritization, while it is employed to determine the priorities of the alternatives.

According to the results that obtained from AHP, when the weight matrix of the criteria and the weight matrix of the software were multiplied, the ProcessMaker to be used with the highest percentage was selected which is $65.74 \%$.

\section{CONCLUSIONS}

Companies need to maintain a high standard of quality and operative processes in order to develop their business and grow it to become a leader in its field. BPM's improve business processes by getting rid of redundancies, improving quality control, and highlighting areas where businesses can reduce costs. For this reason, more companies are embracing BPM's - Business Process Management software.

Finding the best BPM solution is key to not only identifying processes that needs to be improved but also to reach the company goals. To choose a BPM, companies will need to consider several factors.

In this paper, a multi stage decision approach is provided for BPM software selection problem. This problem is based on comparison of software alternatives according to identified criteria. In this paper, respectively NGT, Delphi, and AHP methods were applied in order to determine the most suitable software for the company.

The purpose of this article is to select the BPM software that best fits the criteria, after determining the criteria to be considered. With its multi staged structure focus on BPM software, it differs from the software selection literature.

The difference of this study is to provide a newly established company with improve efficiencies, better customer relations, employee satisfaction, and decrease the waste-time reduction. For this purpose, with this study chose the most efficient and suitable BPM software for the company.

Today, there are many BPM tools that can help businesses improve their processes in an easy way. An initial investment into BPM software could save companies more in the long term than they would expect.

The selection of BPMs is a multi-criteria decision process, and therefore an appropriate method should be used to make very objective decisions. The methods applied in this study suggest different possible criteria 
Journal of Global Strategic Management | V. 15 | N. 2 | 2021-December| isma.info | 107-131 | DOI: 10.20460/JGSM.2022.306

and specific techniques to be used, but these methods do not facilitate the selection process of the BPM software.

Some criteria could have a quantitative structure or have a certain structure which can be measured precisely. In such cases, other MCDM methods can be used to obtain the evaluation matrix. This will improve the proposed method and is one of the directions in for future research. 


\section{REFERENCES}

3 ProcessMaker Features to Boost Your Process Optimization Strategy. (2020). Retrieved from https://www.processmaker.com: https://www.processmaker.com/blog/3-processmaker-features-to-boostyour-process-optimization-strategy/

Ali, A. (2015). An MCDM approach towards m-payment business models evaluation. International Journal of the Analytic Hierarchy Process, 7(2), 273-294.

Ammarapala, V., Chinda, T., Pongsayaporn, P., Ratanachot, W., Punthutaecha, K., \& Janmonta, K. (2018). Cross-border shipment route selection utilizing analytic hierarchy process (AHP) method. Songklanakarin J. Sci. Technol, 40, 31-37.

BPM Institute. (2016). Selection Criteria for BPM Software. Retrieved from https://www.bpminstitute.org: https://www.bpminstitute.org/resources/articles/selection-criteria-bpmsoftware

Brkić, L., Tomičić Pupek, K., \& Bosilj Vukšić, V. (2020, 8). A framework for bpm software selection in relation to digital transformation drivers. Tehnicki Vjesnik, 27(4), 1108-1114. Retrieved from https://doi.org/10.17559/TV-20190315193304

Bruin, T. d., \& Rosemann, M. (2007). Using the Delphi Technique to Identify BPM. ACIS 2007, (pp. 643-653).

Dalkey, N., \& Helmer, O. (1963). An Experimental Application of the Delphi Method to the Use of Experts. Management Science.

Ghlala, R., Kodia, Z., \& Said, L. B. (2017). Mc-DMN: Meeting MCDM with DMN involving multicriteria decision-making in business process. International Conference on Computational Science and Its Applications (pp. 3-16). Springer.

Harvey, N., \& Holmes, C. (2012). Nominal group technique: An effective method for obtaining group consensus . International Journal of Nursing Practice, 188-194.

Hsu, C.-C., \& Sandford, B. A. (2007). The Delphi Technique: Making Sense of Consensus. Practical Assessment Research \& Evaluation, 1-8.

K2 Software. (2020). Retrieved from https://www.nintex.com: https://www.nintex.com/workflowautomation/k2-software/

Kim, D. Y., Baek, N. K., Lee, D. H., \& Lim, H. C. (2018). A Preliminary Study on the Priority of Business Evaluating Model for Design Office. MATEC Web of Conferences. 167, p. 01003. EDP Sciences. doi:https://doi.org/10.1051/matecconf/201816701003

Kissflow. (2020, September 11). A Full Overview of Business Process Management (BPM). Retrieved from https://kissflow.com: https://kissflow.com/bpm/business-process-management-overview/

Kissflow Business Process Management Software. (2020). Retrieved from https://kissflow.com: https://kissflow.com/business-process-management-software/

Kohlenbach, T. (2018, March 16). How to choose the right process management software. Retrieved from https://www.processexcellencenetwork.com: https://www.processexcellencenetwork.com/businessprocess-management-bpm/articles/how-to-choose-the-right-process-management

Landeta, J., Barrutia, J., \& Lertxundi, A. (2011). Hybrid Delphi: A methodology to facilitate contribution from experts in. Technological Forecasting \& Social Change.

Ma, J. Y., Kim, B. W., Seo, Y. H., Leem, C. S., \& Moon, H. (2012). An integrated Method for Business Process Improvement. International Journal of Innovative Computing, Information and Control, 8(7), 5237-5250.

Macphail, A. (2001). Nominal group technique: a useful method for working with young people. British Educational Research Journal, 161-170.

Macphail, A. (2010). Nominal Group Technique: A useful method for working with young. British Educational Research Journal, 161-170. 
PAT Research. (2018, March 31). HOW TO SELECT THE BEST BUSINESS PROCESS MANAGEMENT (BPM) SOFTWARE FOR YOUR BUSINESS. Retrieved from https://www.predictiveanalyticstoday.com/: https://www.predictiveanalyticstoday.com/what-is-businessprocess-management-software/

Pourjavad, E., \& Shirouyehzad, H. (2011). A MCDM approach for prioritizing production lines: a case study. International Journal of Business and Management, 6(10), 221-229.

ProcessMaker. (2020). Retrieved from https://www.capterra.com: https://www.capterra.com/p/118311/ProcessMaker-BPM-Software/

ProcessMaker Features. (n.d.). Retrieved from https://www.g2.com: https://www.g2.com/products/processmaker/features

Robledo, P. (2018). How to select a BPM software? Retrieved from https://albatian.com: https://albatian.com/en/blog-ingles/how-to-select-a-bpm-software/

Sebetci, O., Günay, M. B., \& Sebetci, E. (2018). İş Süreç Yönetimi (Bpm) ve İş Akış Yönetimi (Wfm) Kavramlarına . Online Academic Journal of Information Technology, 116-126.

Seysane, H. (2018, August 3). Business Process Model and Notation (BPMN). Retrieved from https://medium.com: https://medium.com/@seysane/business-process-management-notation1e51d945e877\#: :text=D\%C3\%B6rt\%20b\%C3\%B61\%C3\%BCme\%20ayr\%C4\%B1lan \%20bu\%20makal ede,olarak\%20birlikte $\% 20$ nas $\% C 4 \% \mathrm{~B} 11 \% 20 \% \mathrm{C} 3 \% \mathrm{~A} 7 \mathrm{al} \% \mathrm{C} 4 \% \mathrm{~B} 1 \% \mathrm{C} 5 \% 9 \mathrm{Ft} \% \mathrm{C} 4 \% \mathrm{~B} 1 \mathrm{klar} \% \mathrm{C} 4 \% \mathrm{~B} 1 \% 20$ $\mathrm{a} \% \mathrm{C} 3 \% \mathrm{~A} 7 \% \mathrm{C} 4 \% \mathrm{~B} 1$ klanacakt $\% \mathrm{C} 4 \% \mathrm{~B} 1 \mathrm{r}$

Štemberger, M. I., \& Vuksic, V. B. (2009). Business Process Management Software Selection - Two Case Studies. Economic research-Ekonomska istraživanja, 22(4), 84-99.

ŞAHIN, A. E. (2001). DELPHI TECHNIQUE AND ITS USES IN EDUCATIONAL RESEARCH. Hacettepe Üniversitesi Eğitim Fakültesi Dergisi, 20(20), 215-220.

Şen, C. G., \& Cenkçi, D. (2009). An Integrated Approach to Determination and Evaluation of Production Planning Performance Criteria. Journal of Engineering and Natural Sciences, 27, 1-19.

Taylan, H. H. (2011). The Comparison of Content Analysis and Discourse Analysis Which. Bingöl Üniversitesi Sosyal Bilimler Enstitüsü Dergisi, 1(2), 63-76.

TrustRadius. (2020). List of Top Business Process Management (BPM) Tools 2020. Retrieved from https://www.trustradius.com/business-process-management-bpm

Zuhaira, B., \& Ahmad, N. (2020). Business process modeling, implementation, analysis, and management: the case of business process management tools. Business Process Management Journal, 139. 